\title{
The Nerve Growth Factor-Inducible Large External (NILE) Glycoprotein and Neural Cell Adhesion Molecule (N-CAM) Have Distinct Patterns of Expression in the Developing Rat Central Nervous System
}

\author{
Lora Beasley and William B. Stallcup \\ Cancer Research Center, La Jolla Cancer Research Foundation, La Jolla, California 92037
}

\begin{abstract}
The nerve growth factor-inducible large external (NILE) glycoprotein and the neural cell adhesion molecule (N-CAM) have both been implicated in the process of nerve fiber fasciculation. To evaluate the respective roles of the 2 molecules in fiber tract formation, we used immunohistochemical means to compare their distributions in the developing rat central nervous system. In the spinal cord, hindbrain, forebrain, retina, and cerebellum, N-CAM was present on undifferentiated cells in germinal zones as well as on differentiating cells and in nerve fiber tracts. In contrast, NILE was restricted to the developing fiber tracts in all these areas. No fiber tracts were found that were obviously lacking one or the other of the $\mathbf{2}$ molecules during the period of tract development. However, in all cases except that of the cerebellar molecular layer, nerve fiber tracts appeared to lose NILE and retain N-CAM after the major phases of tract dovelopment were completed. The fact that NILE is restricted to nerve fiber tracts during relatively short but crucial phases of tract development suggests that NILE plays a very specific role in the formation of fiber bundles. The more ubiquitous N-CAM molecule may have a more general role in neural histogenesis.
\end{abstract}

The orderly development of the nervous system is dependent in part on the ability of neural cells to recognize and interact with one another according to very specific patterns. It is widely believed that cell-surface molecules mediate cell-cell recognition and adhesion, and work in a number of laboratories has led to the identification of an expanding array of molecules that may be involved in these processes. One such molecule is the nerve growth factor-inducible large external (NILE) glycoprotein, a 230,000 Da cell-surface molecule first identified on PC12 cells (McGuire et al., 1978). Antibodies prepared against NILE have been used to demonstrate that an immunologically crossreactive family of NILE-like glycoproteins, ranging from 215,000 to $230,000 \mathrm{Da}$, is expressed by neuronal cell lines and neurons in primary cultures prepared from the rat nervous system (Salton et al., 1983a, b; Stallcup et al., 1983; Stallcup and Beasley,

\footnotetext{
Received May 30, 1986; revised Sept. 26, 1986; accepted Oct. 2, 1986.

This work was supported by NIH Grant NS 21990 and a Muscular Dystrophy Association grant to W.B.S. We wish to thank Dr. Gerald Edelman for providing us with rabbit antibody against N-CAM.

Correspondence should be addressed to William B. Stallcup, La Jolla Cancer Research Foundation, 10901 North Torrey Pines Road, La Jolla, CA 92037.

Copyright (c) 1987 Society for Neuroscience $0270-6474 / 87 / 030708-08 \$ 02.00 / 0$
}

1985b). Using fluorescence immunohistochemistry with frozen tissue sections, we have shown that NILE is difficult to detect in immature neurons and on the cell bodies of differentiating neurons, but is readily detectable on axonal projections in developing nerve fiber tracts of the rat nervous system (Stallcup et al., 1985). NILE may play an important role in the formation of these fiber tracts, as evidenced by the finding that antibody against NILE is effective in blocking neurite fasciculation in cultures of embryonic rat brain (Stallcup and Beasley, 1985a).

In terms of its relationship to other components involved in neuronal recognition, NILE has recently been shown by immunological comparisons to be very similar or identical to the neuron-glia cell adhesion molecule (Ng-CAM) and to the L1 adhesion molecule. The high-molecular-weight forms of $\mathrm{Ng}$ CAM and $\mathrm{L} 1(>200,000 \mathrm{Da})$ cross-react strongly with antibodies against NILE and comigrate with NILE on SDS-PAGE (Bock et al., 1985; Friedlander et al., 1986; Sajovic et al., 1986). In spite of these molecular similarities, there is not yet general agreement as to the role that NILE, Ng-CAM, and L1 play in histogenesis. For example, Ng-CAM was initially thought to be involved only in neuron-glia interactions (Grumet et al., 1984a), but is now believed to be involved in both neuron-glia and neuron-neuron interactions (Grumet et al., 1984b; Hoffman et al., 1986). L1 has been found to mediate neuron-neuron but not neuron-glia interactions (Keilhauer et al., 1985). Furthermore, $\mathrm{L} 1$ has been implicated in axon fasciculation in postnatal cerebellar cultures (Fischer et al., 1986), while NILE appears to mediate fasciculation of axons in embryonic brain cultures but not in cultures of postnatal cerebellum (Stallcup and Beasley, 1985a). It is possible that these discrepancies result more from differences in the antibodies used for the studies than from differences in the glycoproteins, but until it is resolved, the question of NILE:Ng-CAM:L1 identity requires further study. It is clear, however, that the NILE:Ng-CAM:L1 class of molecules is distinct from N-CAM, which is also involved in neuronal cell adhesion and in neurite fasciculation (Edelman, 1983; Rutishauser, 1983). Immunochemical, electrophoretic, and proteolytic peptide comparisons have confirmed the separate identities of the 2 classes of adhesion molecules (Faissner et al., 1984a; Grumet et al., 1984a; Rathjen and Rutishauser, 1984; Stallcup and Beasley, 1985b).

Since we have found that antibodies against NILE and against $\mathrm{N}-\mathrm{CAM}$ have nonidentical effects on fasciculation in different types of primary culture systems (Stallcup and Beasley, 1985a), it becomes important to assess the respective contributions made by NILE and N-CAM to the process of fiber tract formation in 
different arcas of the devcloping ncrvous systcm. Onc mcans of addressing this problem is to compare the appearance and distributions of NILE and N-CAM in fiber tracts. Theoretically, fasciculation in any given fiber tract might involve (1) preferential expression of one or the other of the 2 molecules, (2) sequential expression of the 2 molecules, or (3) parallel expression of the 2 molecules.

Although some comparisons of Ng-CAM to N-CAM and of L1 to N-CAM have been published (see Discussion), a direct comparison of NILE to N-CAM expression has not yet been presented. Since the precise relationship of NILE to Ng-CAM and L1 has not yet been firmly established, and since it is important to obtain a more comprehensive comparison of NILE to $\mathrm{N}$-CAM expression in mammals to complement the available data on $\mathrm{Ng}$-CAM and $\mathrm{N}$-CAM in the chick, we have studied the appearance and distribution of NILE and N-CAM immunoreactivity in several parts of the developing rat nervous system. We have not only tried to compare the schedules for expression of NILE and N-CAM in the different regions, but to establish how exclusively the 2 molecules are expressed in fiber tracts, as opposed to other structures. The results of our study reinforce previous conclusions concerning the similarity of NILE to NgCAM and L1 and further illustrate the differences that exist between the patterns of NILE and N-CAM expression in the CNS.

\section{Materials and Methods}

Antisera. Preparation of rabbit antiserum against the NILE glycoprotein has been previously described. This antibody has been used to investigate the biochemistry, distribution, and function of NILE (Stallcup et al., 1983, 1985; Stallcup and Beasley, 1985a, b). The antiserum specifically immunoprecipitates NILE-related glycoproteins of 215,000$230,000 \mathrm{Da}$ from a variety of neuronal cell types. Immunofluorescence experiments with the antibody show that NILE is selectively expressed by neurons in both primary cultures and frozen sections. Anti-NILE antibody was used at a $1 / 25$ dilution in the present series of experiments. Rabbit antibody against mouse N-CAM was the generous gift of Dr. Gerald Edelman (Rockefeller University). This antibody is highly crossreactive with rat N-CAM (Chuong et al., 1982). It was used at a 1/50 dilution. Monoclonal antibody against the D1.1 ganglioside has been described previously (Levine et al., 1984, 1986; Stallcup et al., 1984). The D1.1 ganglioside provides a convenient marker for localizing germinal cells of the rat CNS. Tissue culture supernatant from D1.1 hybridoma cultures was used at a $1 / 10$ dilution for immunohistochemistry. Fluorescein-labeled goat antibodies against rabbit and mouse immunoglobulins were purchased from TAGO. They were used at 1/50 dilutions.

Immunohistochemistry. Timed pregnant Sprague-Dawley rats were obtained from Zivic Laboratories. Their embryos and pups were used for our studies. Embryonic tissues were fixed by immersion for $6 \mathrm{hr}$ at $4^{\circ} \mathrm{C}$ in $1 \%$ paraformaldehyde $/ 0.1 \%$ glutaraldehyde buffered with $0.1 \mathrm{M}$ sodium phosphate, $\mathrm{pH}$ 7.2. Tissues were then stored overnight in the same fixative containing $20 \%$ sucrose. Eleven and 12 -d-old embryos were fixed whole, while the brains from older embryos were removed for fixation. Spinal cords of these older embryos were exposed prior to fixation by removing the overlying tissue. Postnatal animals were perfused through the heart with cold $1 \%$ paraformaldehyde $/ 0.1 \%$ glutaraldehyde, $\mathrm{pH}$ 7.2. Brains were removed and postfixed overnight in the same fixative containing $20 \%$ sucrose. Fixed tissues were embedded in OCT compound, and $15 \mu \mathrm{m}$ sections were cut on a LabTek II cryostat microtome. Spinal cords were sectioned in a transverse orientation, while brains were cut horizontally. Sections were mounted on gelatincoated slides.

For immunofluorescent staining, we used adjacent sections to compare the distributions of NILE, N-CAM, and D1.1. All washes and antibody dilutions were made with PBS, pH 7.4, containing $2 \%$ normal goat serum and $0.1 \%$ Triton X-100. Sections were incubated overnight at $4^{\circ} \mathrm{C}$ with primary antiserum, washed twice, and incubated for an additional hour at room temperature with fluorescein-labeled secondary antiserum. Following 2 more washes, slides were rinsed in distilled water, coverslipped in glycerol, and examined with a Nikon Optiphot microscope equipped for epifluorescence. Kodak Tri-X pan film was used for the photography.

\section{Results}

Immunofluorescent staining with anti-NILE and anti-N-CAM was compared in the developing rat spinal cord, hindbrain, forebrain, retina, and cerebellum. In some cases monoclonal antibody against the D1.1 ganglioside was used to locate germinal zones of the CNS (Levine et al., 1984, 1986; Stallcup et al., 1984).

\section{Spinal cord}

Staining with anti-NILE antibody first appeared in the spinal cord on embryonic day eleven (E11) as a very thin rim of fibers in the outer margin of the ventral cord (Stallcup et al., 1985). By E12, NILE-positive fiber tracts were clearly visible in the ventral and lateral funiculi of the cord (Fig. 1c). Germinal cells in the interior regions of the cord were negative for NILE. Antibody against N-CAM also stained fiber bundles in the developing funiculi, but, in addition, this antibody showed that $\mathrm{N}-\mathrm{CAM}$ was present on germinal cells in the ventricular zones of the cord (Fig. $1 b$ ).

At E14, the dorsal, ventral, and lateral funiculi were intensely stained with anti-NILE antibody (Fig. $1, f, h$ ). Germinal cells lining the central canal (indicated by staining with anti-D1.1 antibody in Fig. 1d) did not express NILE. Cells in the intermediate zones were also negative for NILE. In contrast, anti$\mathrm{N}-\mathrm{CAM}$ brightly labeled both the fiber tracts and cells in the intermediate zones of the $\mathrm{E} 14$ spinal cord (Fig. 1e). At higher magnification, it was apparent that germinal cells in the ventricular zone also expressed N-CAM (Fig. 1g). At E18 these relative patterns of NILE and N-CAM distribution remained much the same, although the funiculi were more extensive and the germinal zones were smaller than at E14 (not shown).

In the spinal cord of the newborn rat, N-CAM was still easily detectable in the funiculi, as well as on cells of the more interior zones (Fig. 1, $i, k$ ). In contrast, the funiculi were only weakly labeled by anti-NILE antibody at this stage of development (Fig. $1, j, l)$.

\section{Brain}

\section{Hindbrain}

The patterns of anti-NILE and anti-N-CAM staining in the developing rhombencephalon and mesencephalon were very similar to those observed in the spinal cord. At E12, $1 \mathrm{~d}$ after the first appearance of NILE in the hindbrain, anti-NILE labeling was confined to fiber tracts of the marginal zones of the rhombencephalon and mesencephalon (Fig. 2c). Cells in the ventricular portions of these areas were not labeled by antiNILE. Anti-N-CAM intensely stained the fiber tracts in the marginal zones and, more faintly, the germinal cells of the ventricular zones (Fig. 2b).

At E14, the differences between the staining patterns of the 2 antibodies were more marked. NILE was detected in fiber tracts of the marginal and intermediate zones of the rhombencephalon (Fig. 2f) and mesencephalon (not shown). Cells of the germinal zones, located by staining with anti-D1.1 antibody (Fig. 2d), were negative for NILE. In contrast, cells in the germinal zones were labeled by anti-N-CAM, as were cell bodies and fibers in the intermediate and marginal zones (Fig. 2e). As 

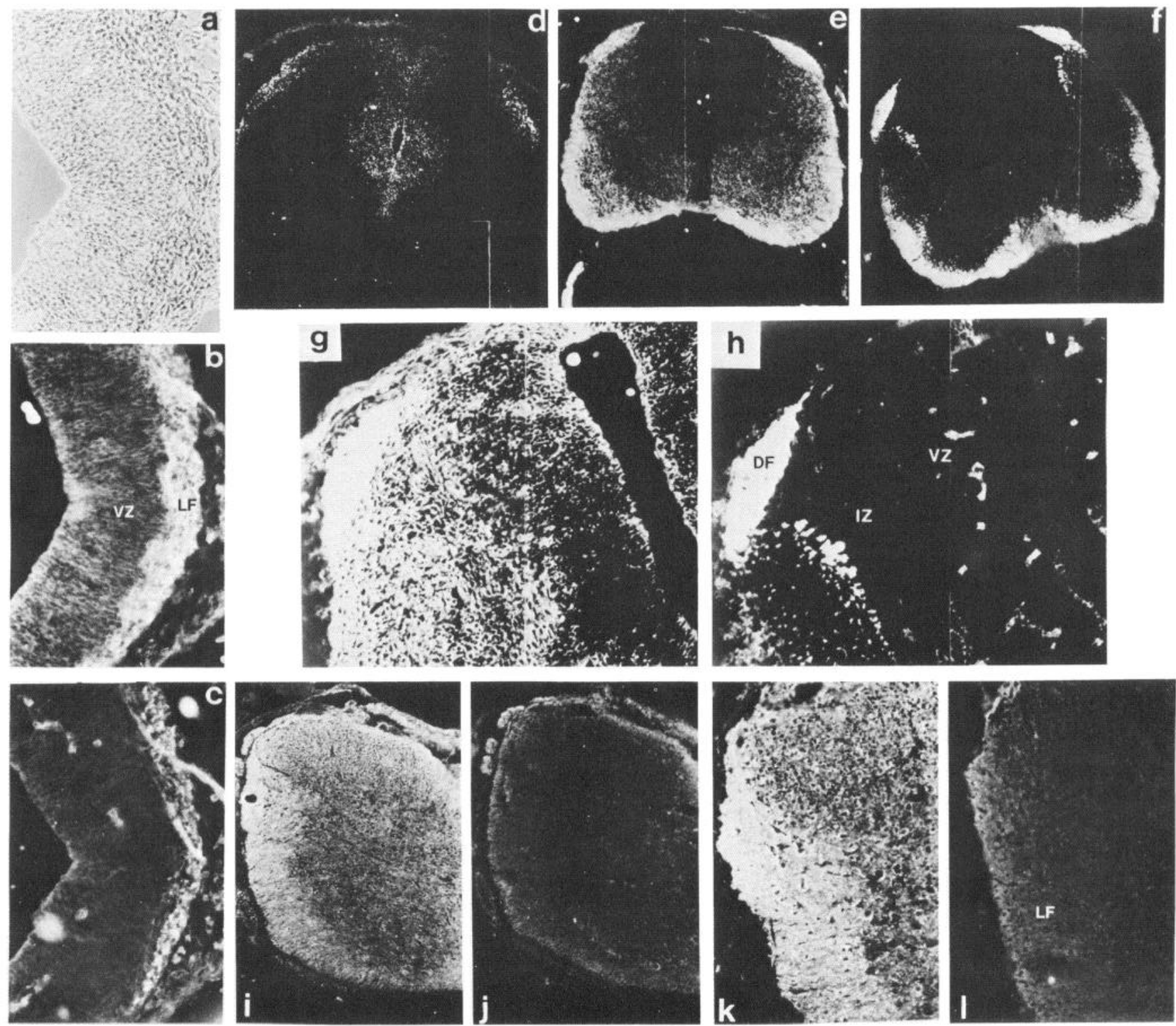

Figure 1. NILE and N-CAM in the spinal cord. $a-c$, Embryonic day 12. $a$, Phase. $b$, Anti-N-CAM. $c$, Anti-NILE. $\times 180 . d-f$, Embryonic day 14 . $d$, Anti-D1.1. $e$, Anti-N-CAM. $f$, Anti-NILE. $\times 100 . g, h$, Embryonic day $14 . g$, Anti-N-CAM. $h$, Anti-NILE. $\times 240 . i, j$, Postnatal day $1 . i$, AntiN-CAM. $j$, Anti-NILE. $\times 180 . k, l$, Postnatal day $1 . k$, Anti-N-CAM. $l$, Anti-NILE. $\times 200 . V Z$, Ventricular zone; $I Z$, intermediate zone; $D F$, dorsal funiculus; $L F$, lateral funiculus.

in the case of the spinal cord, the presence of N-CAM on both cell bodies and fibers made it difficult to identify the fiber tracts in sections of hindbrain stained with anti-N-CAM. These fiber tracts were clearly visible in anti-NILE-stained sections because NILE was mostly absent from the cell bodies interspersed among the fibers.

\section{Forebrain}

At E14, NILE was seen in fiber tracts in the marginal zone of the diencephalon (Fig. $2 i$ ), but was not present in the germinal zone identified by staining with anti-D1.1 (Fig. 2g). N-CAM, however, was present in both the fiber zone and germinal zone (Fig. 2h).

NILE first appeared in the telencephalon at E15 on fibers of the deep white tract (Stallcup et al., 1985). As the cortex developed, this tract was overlaid by cells of the growing cortical plate. Figure $2 k$ shows anti-NILE staining of the E18 deep white tract at the point where fibers enter the ganglionic eminence to form the internal capsule. Figure $2 m$ shows the deep white tract at higher magnification in the posterior telencephalon. Anti-NCAM stained not only the NILE-positive deep white tract, but also cells on both sides of the tract (Fig. 2, $j, l$ ).

As noted in the case of the spinal cord, although staining with anti-N-CAM was still seen during the first postnatal week, NILE became progressively more difficult to detect in the hindbrain and forebrain after birth. Tracts that were positive for NILE at E18 were only weakly stained by anti-NILE on postnatal days 1 and 2 (P1 and P2; not shown).

\section{Retina}

In the retina, NILE could first be detected on the developing optic nerve at E13. At E14, this staining with anti-NILE in the optic nerve was more pronounced, and a small amount of staining could be found on the axons of the retinal ganglion cells, 

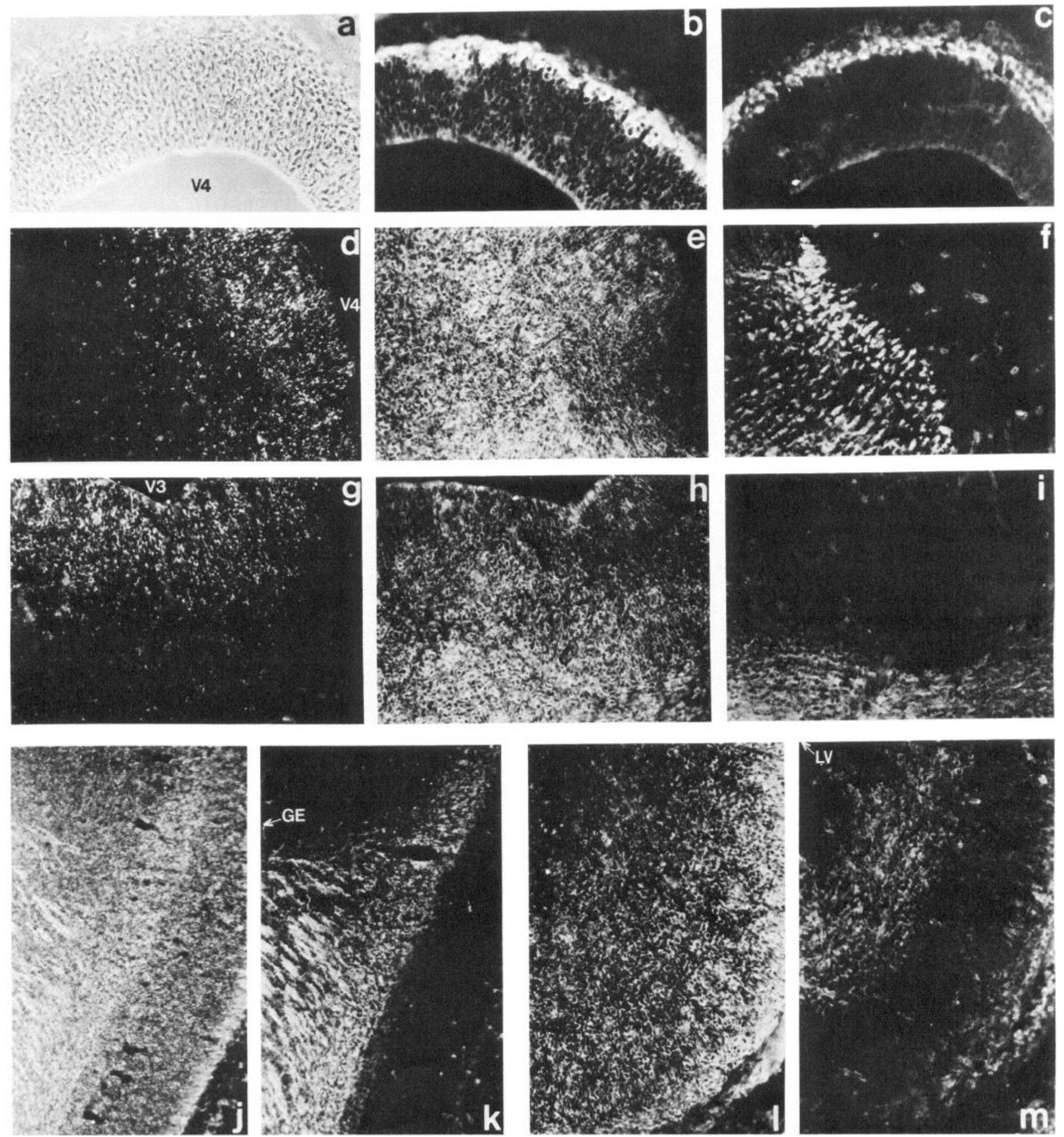

Figure 2. NILE and N-CAM in the brain. $a-c$, Embryonic day 12 rhombencephalon. $a$, Phase. $b$, Anti-N-CAM. $c$, Anti-NILE. $\times 190 . d-f$, Embryonic day 14 rhombencephalon. $d$, Anti-D1.1. $e$, Anti-N-CAM. $f$, Anti-NILE. $\times 190 . g-i$, Embryonic day 14 diencephalon. $g$, Anti-D1.1. $h$, Anti-N-CAM. $i$, Anti-NILE. $\times 190 . j, k$, Embryonic day 18 lateral telencephalon. $j$, Anti-N-CAM. $k$, Anti-NILE. $\times 115 . l, m$, Embryonic day 18 posterior telencephalon. $l$, Anti-N-CAM. $m$, Anti-NILE. $\times 225$. $V 4$, Fourth ventricle; $V 3$, third ventricle; $L V$, lateral ventricle; $G E$, ganglionic eminence.

which lie on the inner surface of the retina and merge to form the optic nerve. By E15, both this inner fiber layer of the retina and the optic nerve were very clearly labeled by anti-NILE (Fig. $3 c$ ). During this period from E13 to E15, N-CAM was present on the innermost fiber layer and in the optic nerve, but was also distributed on cell bodies throughout the width of the retina
(Fig. 3b). These staining patterns are shown at higher magnifcation in Figure 3, $d-f$ for the case of the E16 retina. Except for the NILE-positive axons of the retinal ganglion cells, the rat retina was largely undifferentiated at this stage and was stained throughout with both anti-D1.1 (Fig. 3, $a, d$ ) and anti-N-CAM (Fig. 3, b,e). As noted above for the brain and spinal cord, the 
bright staining of cell bodies with anti-N-CAM made it difficult to identify the fiber zones of the retina. Three weeks postnatally, the layers of the mature retina were clearly visible (Fig. $3 g$ ). $\mathrm{N}-\mathrm{CAM}$ was still present on cell bodies in the 2 nuclear layers and was especially evident in the plexiform layers and fiber zones (Fig. $3 h$ ). Except for some staining in the outer plexiform layer, anti-NILE showed very little reactivity with the fiber zones of the mature retina (Fig. $3 i$ ).

\section{Cerebellum}

At P2, NILE was detected only on fibers in the white matter of the developing cerebellum (Fig. 4c). Staining with anti-N-CAM, however, was seen almost throughout the cerebellar cortex (Fig. $4 b$ ). The lone exception appeared to be the cells of the developing external granule cell layer (EGL). Very similar patterns were seen with the 2 antibodies at P4. NILE was still restricted to the white matter, while N-CAM was absent only from cells of the developing EGL (not shown).

By P7, the molecular layer had begun to form (Fig. $4 d$ ), and this fiber layer was stained by both anti-N-CAM and anti-NILE (Fig. $4, e, f$ ). In contrast to NILE, however, N-CAM was still widespread in the cerebellar cortex. Anti-N-CAM staining was very bright on cells of the internal granule cell layer, and was now apparent on cells of the EGL as well. These patterns of anti-NILE and anti-N-CAM staining were seen more clearly at P10, when both the EGL and molecular layer were larger (Fig. $4, g-i)$. N-CAM was present on the NILE-positive fibers of the molecular layer, and in addition was expressed by cells of both the internal and external granule cell layers.

In contrast to the other areas of the brain that we examined, the molecular layer of the cerebellar cortex retained NILE immunoreactivity into maturity. The distributions of NILE and $\mathrm{N}-\mathrm{CAM}$ in 6-month-old cerebellum are shown in Figures 4, $j-l$. Anti-NILE and anti-N-CAM staining were very similar at this time, although N-CAM appeared to be more abundant than NILE in the granule cell layer.

\section{Discussion}

In the introduction we briefly summarized data that indicate that both NILE and N-CAM are involved in fasciculation and fiber tract formation (see also Stallcup and Beasley, 1985a; Stallcup et al., 1985). Three possible models were outlined for the expression of NILE and N-CAM in any given fiber tract: (1) A fiber tract might express preferentially either NILE or N-CAM. (2) A fiber tract might express the 2 molecules sequentially, with the expression of one following the early expression of the other. (3) A fiber tract might express the 2 molecules in parallel, the expression of one coinciding with the expression of the other. Theoretically, it would be possible for different patterns of NILF and N-CAM expression to occur in different fiber tracts. We observed, however, that the relationship between NILE and $\mathrm{N}$-CAM expression was very similar in different regions of the rat $\mathrm{CNS}$, including the spinal cord, hindbrain, forebrain, retina, and cerebellum. The pattern of expression did not conform precisely to any one of the 3 models outlined above, but displayed features of both the sequential and parallel modes of expression. Three recurrent themes were noted.

1. In all regions examined, undifferentiated germinal cells expressed N-CAM but not NILE. Primary germinal zones lining the ventricles, a secondary germinal zone in the EGL of the cerebellum, and undifferentiated cells in the developing retina were identified using antibody against the D1.1 ganglioside.
Cells in these zones were stained with anti-N-CAM but not with anti-NILE antibody. Thus N-CAM appears very early in the life of neuronal cells, while NILE is expressed only at a later stage of differentiation. In this sense, N-CAM and NILE are expressed sequentially by neurons.

2. During the formation of fiber tracts, N-CAM and NILE were present concurrently. Each molecule was found early in the formation of fiber tracts and continued to be present during subsequent enlargement of the tracts. This was observed in the funiculi of the spinal cord, in the marginal and intermediate zones of the hindbrain and forebrain, in the axonal layers of the retina and optic nerve, and in the white matter and molecular layer of the cerebellar cortex. Thus, during the actual formation of fiber tracts, N-CAM and NILE seem to be present in parallel.

3. In almost all cases, NILE, but not N-CAM, appeared to decrease dramatically once fiber tract formation was completed. We observed large decreases in anti-NILE labeling of the spinal cord, forebrain, hindbrain, retina, and white matter of the cerebellum. The one exception to this general pattern was the molecular layer of the mature cerebellum, in which both NILE and $\mathrm{N}-\mathrm{CAM}$ were readily detectable.

These 3 generalizations concerning NILE and N-CAM expression are largely consistent with other comparisons of N-CAM cxpression with $\mathrm{Ll}$ and $\mathrm{Ng}-\mathrm{CAM}$ cxpression. With regard to the presence of these molecules on undifferentiated cells, it has been demonstrated that N-CAM appears very early in the development of the chick nervous system (Thiery et al., 1982; Edelman et al., 1983). Cells of the neural plate and neural tube express N-CAM, as do pre- and postmigratory neural crest cells. Germinal cells of the embryonic chick spinal cord, optic tectum, and neural retina express $\mathrm{N}-\mathrm{CAM}$ but not $\mathrm{Ng}-\mathrm{CAM}$ (Daniloff et al., 1986). The proliferating cells of the cerebellar external granule cell layer are positive for N-CAM in both the chick (Grumet et al., 1984b; Daniloff et al., 1986) and mouse (Langley et al., 1983; Rathjen and Rutishauser, 1984), but are negative for Ng-CAM (Grumet et al., 1984b; Thiery et al., 1985; Daniloff et al., 1986) and L1 (Faissner et al., 1984b; Rathjen and Rutishauser, 1984; Rathjen and Schachner, 1984). Finally, ventricular neuroepithelial cells of the embryonic mouse telencephalon express N-CAM but not L1 (Fushiki and Schachner, 1986). These observations are all in accord with our finding that throughout the nervous system N-CAM is present on neuronal precursor cells prior to the appearance of NILE.

Other studies are also in agreement with our conclusion that there is concurrent expression of the 2 classes of cell adhesion molecules in fiber zones. In the chick, N-CAM and Ng-CAM are seen together in the funiculi of the developing spinal cord, in the optic fiber layer and the internal plexiform layer of the retina, and in optic fibers innervating the tectum as well as fiber zones intrinsic to the tectum (Daniloff et al., 1986). The molecular layer and white matter of the cerebellar cortex both express N-CAM and Ng-CAM in the chick (Grumet et al., 1984b; Daniloff et al., 1986) and N-CAM and L1 in the mouse (Langley et al., 1983; Faissner et al., 1984b; Rathjen and Rutishauser, 1984). In the mouse telencephalon, both $\mathrm{L} 1$ and N-CAM are found in fiber tracts of the marginal and intermediate zones (Fushiki and Schachner, 1986). It is clear in each of the above studies, as well as in our study, that N-CAM is not restricted to fiber tracts, but is expressed in varying amounts on nearly all cellular and fiber layers in all areas of the developing nervous system. The NILE:Ng-CAM:L1 class of molecules is much more tightly restricted to fiber tracts, although some types of neuronal 

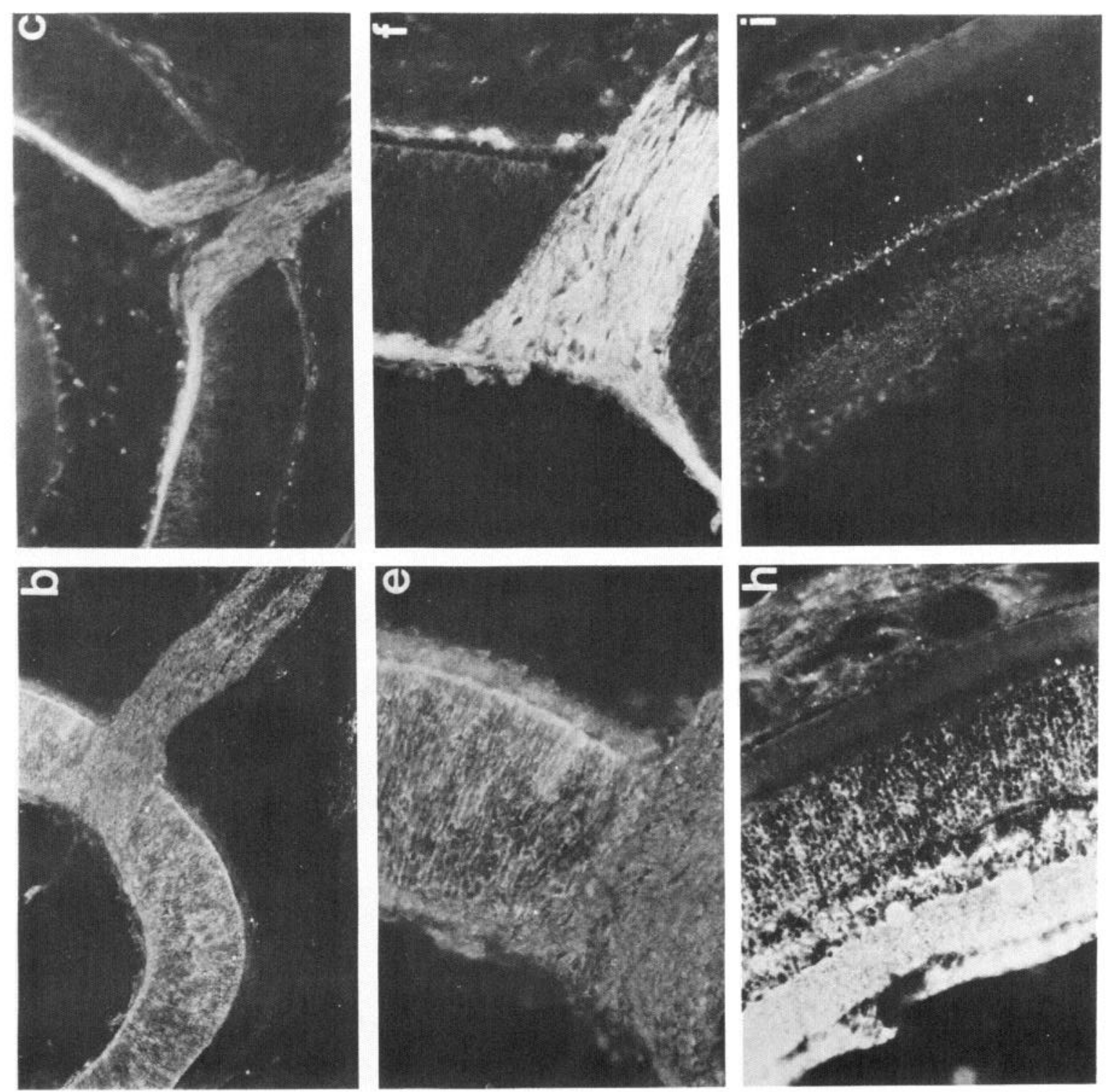

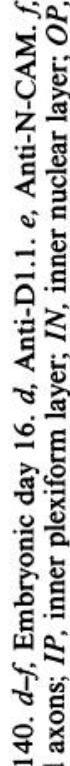
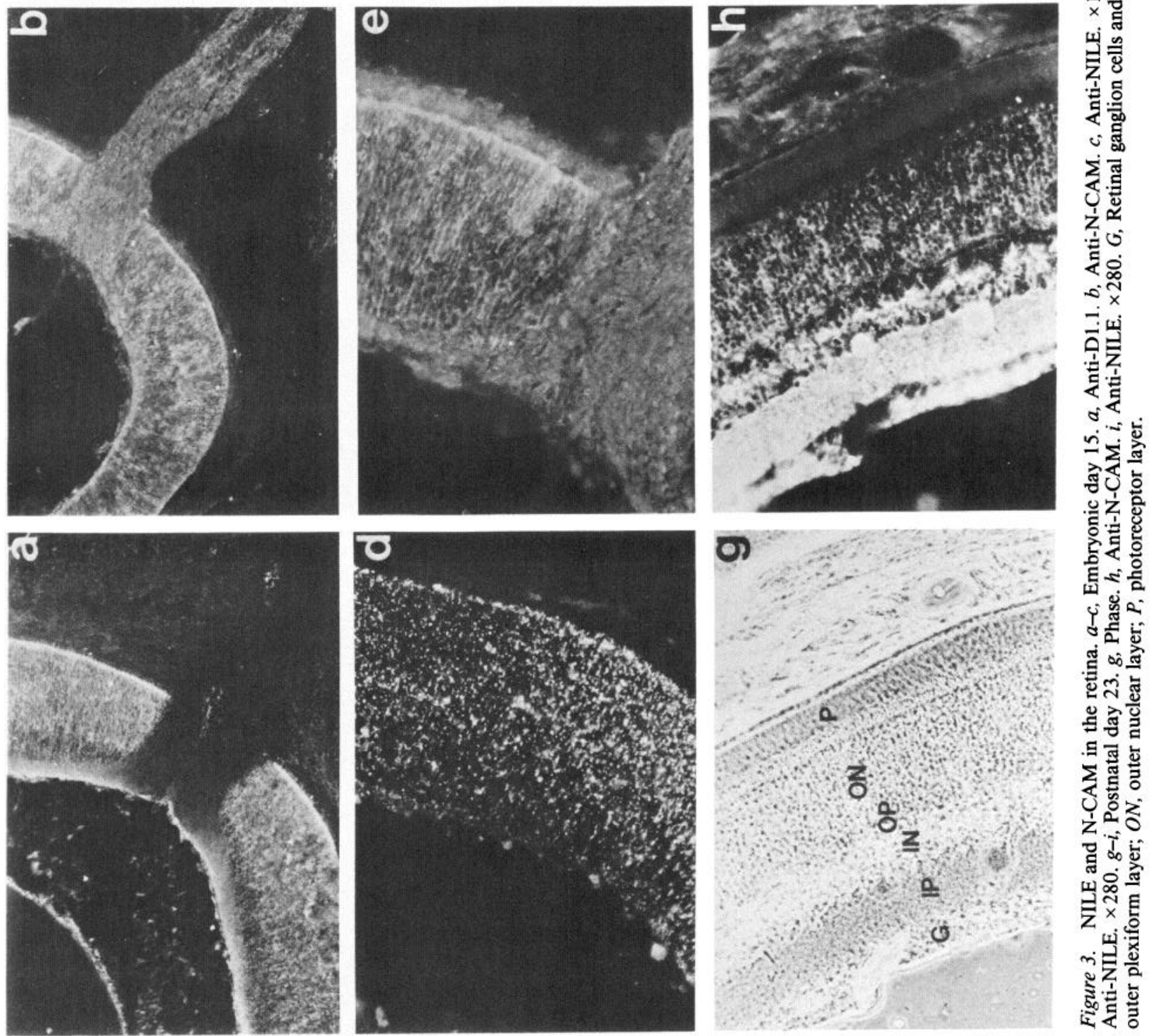

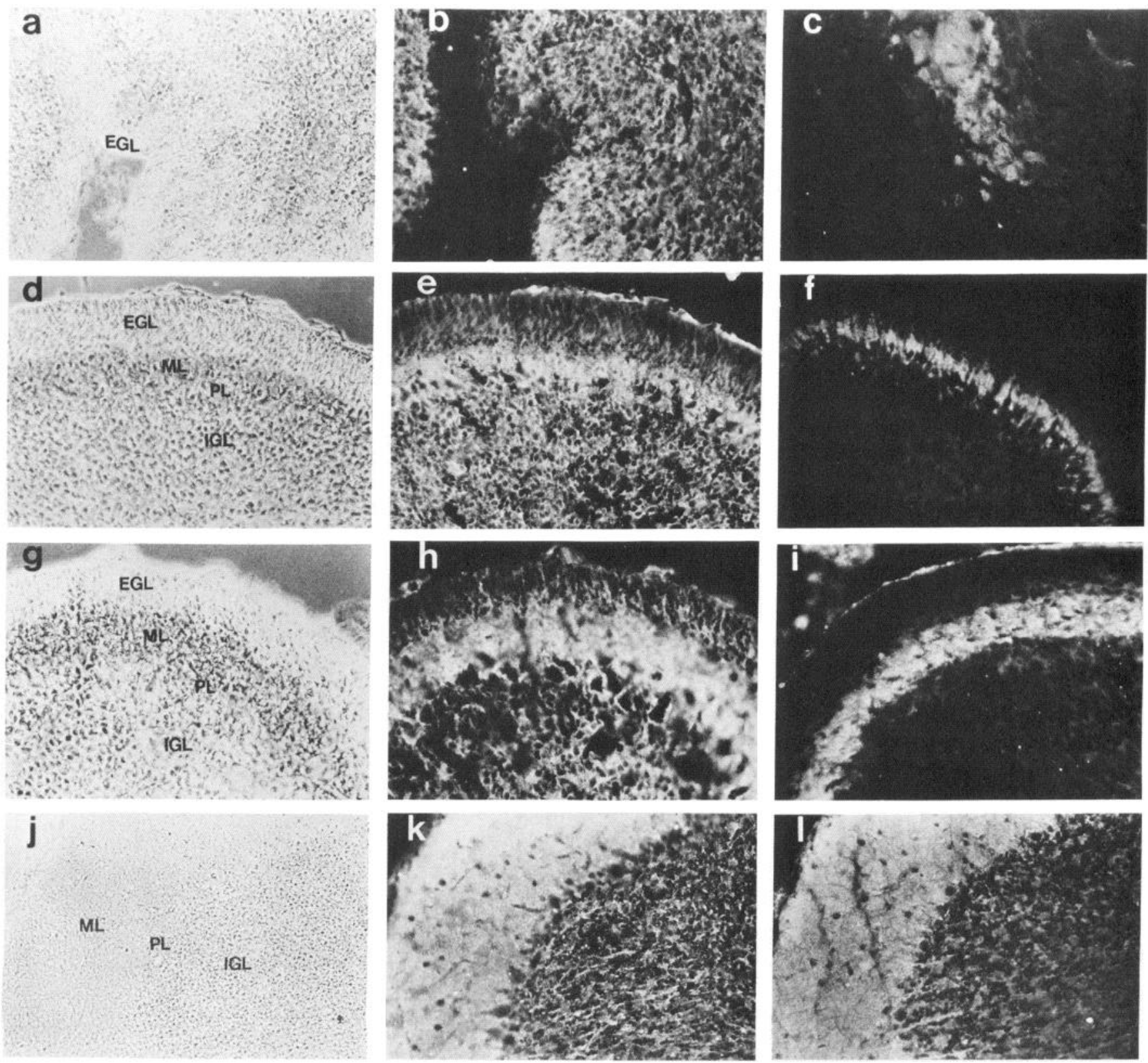

Figure 4. NILE and N-CAM in the cerebellum. $a-c$, Postnatal day 2. $a$, Phase. $b$, Anti-N-CAM. $c$, Anti-NILE. $\times 225 . d-f$, Postnatal day 7. $d$, Phase. $e$, Anti-N-CAM. $f$, Anti-NILE. $\times 225 . g-i$, Postnatal day $10 . g$, Phase. $h$, Anti-N-CAM. $i$, Anti-NILE. $\times 225$. $j-l$, Postnatal day $180 . j$, Phase. $k$, Anti-N-CAM. $l$, Anti-NIL.E. $\times 225$. $E G L$, External granule cell layer; $M L$, molecular layer; $P L$, Purkinje cell layer; $I G L$, internal granule cell layer.

cell bodies are positive for these molecules. The most consistently noted cells of this type are immature, postmitotic granule neurons that are beginning their migration from the cerebellar external granule cell layer (Faissner et al., 1984b; Grumet et al., 1984b; Rathjen and Schachner, 1984; Daniloff et al., 1986). Neuronal soma of the cortical plate and subplate of the developing mouse telencephalon have also been reported to be transiently positive for L1 (Fushiki and Schachner, 1986).

Regarding the loss of NILE immunoreactivity from fiber zones in the more mature nervous system, we have previously suggested a correlation between myelination and the disappearance of staining with anti-NILE antibody (Stallcup et al., 1985). In particular, we observed that unmyelinated fiber tracts of the $\mathrm{CNS}$, such as the olfactory nerve and cerebellar molecular layer, continued to stain with anti-NILE antibody in the adult rat.
Similar observations have been made for Ng-CAM in the chick CNS (Daniloff et al., 1986). Tracts that became myelinated were observed to lose Ng-CAM immunoreactivity, while unmyelinated tracts were still Ng-CAM-positive in the adult. The latter areas included the molecular layer of the cerebellum, the olfactory nerve, and the gray matter of the dorsal and ventral horns of the spinal cord. L1 immunoreactivity is also retained in the molecular layer of the adult mouse cerebellum (Rathjen and Schachner, 1984). It is not known whether the loss of NILE: Ng-CAM:L1 immunoreactivity in most parts of the adult CNS represents an actual decrease in the amount of these molecules or a process, such as myelination, resulting in the masking of antigenic components so that they are not accessible to antibody. The fact that staining of myelinated tracts is still obtained with anti-N-CAM might be taken as evidence that accessibility to 
antibody is not a problem. However, the topographical orientation and interaction of NILE and N-CAM with the sheath need not be identical and, furthermore, N-CAM may be present on glial elements associated with fiber tracts (Noble et al., 1985). Thus, an explanation for the loss of NILE immunoreactivity will require further investigation.

The ubiquitous nature of N-CAM in the developing CNS suggests that it must play an earlier and more general role in histogenesis than NILE, which is restricted to fiber tracts. At first glance, the widespread distribution of N-CAM makes it difficult to imagine how this molecule can contribute in a specific manner to neural pattern formation. However, it has been pointed out that modulation of the structure and amount of a cellsurface molecule can produce differences in cell-cell adhesiveness (Steinberg, 1970; Edelman, 1983). Immunofluorescence with the anti-N-CAM antibody we used does not allow us to detect changes in the structure of N-CAM, such as conversion from the embryonic to adult forms, but it does give an indication of changes in the level of expression. For example, germinal cells appear to have less N-CAM on their surfaces than more mature cells or nerve fibers. This type of modulation may give N-CAM-mediated interactions a degree of flexibility that enables them to be a dynamic rather than static force in histogenesis. Nevertheless, other molecules, such as NILE, which are characteristic of a more differentiated state of the neuron and are localized more exclusively on axonal projections, may be required for further structuring and fine-tuning of processes involved in fiber tract formation. In contrast to N-CAM, NILE first appears on axons involved in fiber tract formation, is largely restricted to axonal surfaces rather than cell bodies, and usually disappears once fiber tract formation is completed. These observations indicate that NILE plays a more specialized role than $\mathrm{N}-\mathrm{CAM}$ in the dynamics of fiber tract development.

\section{References}

Bock, E., C. Richter-Landsberg, A. Faissner, and M. Schachner (1985) Demonstration of immunochemical identity between the nerve growth factor inducible large external (NILE) glycoprotein and the cell adhesion molecule L1. EMBO J. 4: 2765-2768.

Chuong, C.-M., D. McClain, P. Streit, and G. Edelman (1982) Neural cell adhesion molecules in rodent brains isolated by monoclonal antibodies with cross-species reactivity. Proc. Natl. Acad. Sci. USA 79: 4234-4238.

Daniloff, J., C.-M. Chuong, G. Levi, and G. Edelman (1986) Differential distribution of cell adhesion molecules during histogenesis of the chick nervous system. J. Neurosci. 6: 739-758.

Edelman, G. (1983) Cell adhesion molecules. Science 192: 218-226.

Edelman, G., W. Gallin, A. DeLouvée, B. Cunningham, and J.-P. Thiery (1983) Early epochal maps of two different cell adhesion molecules. Proc. Natl. Acad. Sci. USA 80: 4384-4388.

Faissner, A., J. Kruse, C. Goridis, E. Bock, and M. Schachner (1984a) The neural cell adhesion molecule $\mathrm{L} 1$ is distinct from the N-CAM related group of surface antigens BSP-2 and D2. EMBO J. 3: 733737.

Faissner, A., J. Kruse, J. Nieke, and M. Schachner (1984b) Expression of neural cell adhesion molecule Ll during development, in neurological mutants, and in the peripheral nervous system. Dev. Brain Res. 15: 69-82.

Fischer, G., V. Künemund, and M. Schachner (1986) Neurite outgrowth patterns in cerebellar microexplant cultures are affected by antibodies to the cell surface glycoprotein Ll. J. Neurosci. 6: 605612.

Friedlander, D., M. Grumet, and G. Edelman (1986) Nerve growth factor enhances expression of neuron-glia cell adhesion molecule in PC12 cells. J. Cell Biol. 102: 413-419.

Fushiki, S., and M. Schachner (1986) Immunocytological localization of ccll adhesion molccules $\mathrm{Ll}$ and N-CAM and the shared carbohydrate epitome L2 during development of the mouse neocortex. Dev. Brain Res. 24: 153-167.
Grumet, M., S. Hoffman, and G. Edelman (1984a) Two antigenically related neuronal cell adhesion molecules of different specificities mediate neuron-neuron and neuron-glia adhesion. Proc. Natl. Acad. Sci. USA 81: 267-271.

Grumet, M., S. Hoffman, C.-M. Chuong, and G. Edelman (1984b) Polypeptide components and binding functions of neuron-glia cell adhesion molecules. Proc. Natl. Acad. Sci. USA 81: 7989-7993.

Hoffman, S., D. Friedlander, C.-M. Chuong, M. Grumet, and G. Edelman (1986) Differential contributions of Ng-CAM and N-CAM to cell adhesion in different neural regions. J. Cell Biol. 103: 145-158.

Keilhauer, G., A. Faissner, and M. Schachner (1985) Differential inhibition of neurone-neurone, neurone-astrocyte, and astrocyte-astrocyte adhesion by L1, L2, and N-CAM antibodies. Nature 316: 728-730.

Langley, O., G. Gombos, M. Hirn, and C. Goridis (1983) Distribution of the neural antigen BSP-2 in the cerebellum during development. Int. J. Dev. Neurosci. 1: 393-401.

Levine, J., L. Beasley, and W. Stallcup (1984) The D1.1 antigen: A cell surface marker for germinal cells of the central nervous system. J. Neurosci. 4: 820-831.

Levine, J., L. Beasley, and W. Stallcup (1986) Localization of a neuroectoderm-associated cell surface antigen in the developing and adult rat. Dev. Brain Res. 27: 211-222.

McGuire, J., L. Greene, and A. Furano (1978) NGF stimulates incorporation of fucose or glucosamine into an external glycoprotein in cultured rat $\mathrm{PC} 12$ pheochromocytoma cells. Cell 15: 357-365.

Noble, M., M. Albrechtsen, C. Moller, J. Lyles, E. Bock, C. Goridis, M. Watanabe, and U. Rutishauser (1985) Glial cells express N-CAM/ D2-CAM-like polypeptides in vitro. Nature 316: 725-728.

Rathjen, F., and U. Rutishauser (1984) Comparison of two cell surface molecules involved in neural cell adhesion. EMBO J. 3: 461-465.

Rathjen, F., and M. Schachner (1984) Immunocytological and biochemical characterization of a new neuronal cell surface component (L1 antigen) which is involved in cell adhesion. EMBO J. 3: 1-10.

Rutishauser, U. (1983) Developmental biology of a neural cell adhesion molecule. Nature 310: 549-554.

Sajovic, P., E. Kouvelas, and E. Trenkner (1986) Probable identity of NILE glycoprotein and the high-molecular-weight component of $\mathbf{L l}$ antigen. J. Neurochem. 47: 541-546.

Salton, S., C. Richter-Landsberg, L. Greene, and M. Shelanski (1983a) Nerve growth factor-inducible large external (NILE) glycoprotein: Studies of a central and peripheral neuronal marker. J. Neurosci. 3: 441-454.

Salton, S., M. Shelanski, and L. Greene (1983b) Biochemical properties of the nerve growth factor-inducible large external (NILE) glycoprotein. J. Neurosci. 3: 2420-2430.

Stallcup, W., and L. Beasley (1985a) Involvement of the nerve growth factor-inducible large external glycoprotein (NILE) in neurite fasciculation in primary cultures of rat brain. Proc. Natl. Acad. Sci. USA 82: $1276-1280$.

Stallcup, W., and L. Beasley (1985b) Polymorphism among NILErelated glycoproteins from different types of neurons. Brain Res. 346 : 287-293.

Stallcup, W., L. Arner, and J. Levine (1983) An antiserum against the PC12 cell line defines cell surface antigens specific for neurons and Schwann cells. J. Neurosci. 3: 53-68.

Stallcup, W., L. Beasley, and J. Levine (1984) Cell surface molecules that characterize different stages in the development of cerebellar interneurons. In Molecular Neurobiology, Cold Spring Harbor Symp. Quant. Biol. 48: 761-774.

Stallcup, W., L. Beasley, and J. Levine (1985) Antibody against nerve growth factor-inducible large external (NILE) glycoprotein labels nerve fiber tracts in the developing rat nervous system. J. Neurosci. 5: 10901101.

Steinberg, M. S. (1970) Does differential adhesion govern self-assembly processes in histogenesis? Equilibrium configurations and the emergence of a hierarchy among populations of embryonic cells. $J$. Exp. Zool. 173: 395-433.

Thiery, J.-P., J.-L. Duband, U. Rutishauser, and G. Edelman (1982) Cell adhesion molecules in early chicken embryogenesis. Proc. Natl. Acad. Sci. USA 79: 6737-6741.

Thiery, J.-P., A. DeLouvée, M. Grumet, and G. Edelman (1985) Initial appearance and regional distribution of the neuron-glia cell adhesion molecule in the chick embryo. J. Cell Biol. 100: 442-456. 